\title{
A safer drug supply: a pragmatic and ethical response to the overdose crisis
}

\author{
Mark Tyndall MD ScD
}

\author{
— Cite as: CMAJ 2020 August 24;192:E986-7. doi: 10.1503/cmaj.201618
}

See related article at www.cmaj.ca/lookup/doi/10.1503/cmaj.200191

I $\mathrm{n}$ related research, Crabtree and colleagues ${ }^{1}$ provide an important snapshot of the toxic drug supply fuelling an overdose epidemic that has killed more than 6000 people in British Columbia since 2014. ${ }^{2}$ Their descriptive study of drug overdose deaths involving at least 1 illicit substance identified by the BC Coroners Service from 2015 to 2017 showed that the vast majority were related to synthetic opioids purchased from the illicit market, with prescription opioids playing a minor role. ${ }^{1}$ The authors conclude that strategies to address the current overdose crisis in Canada need to go far beyond opioid deprescribing. I would argue that the only pragmatic and ethical way forward is to offer a regulated, safer supply of opioids, decriminalize drug use, and redeploy resources that are used for drug law enforcement into health and social programs.

The arrival of fentanyl on the streets of Vancouver and other cities across North America reveals the devasting consequences of efforts to interrupt and suppress illicit drugs, commonly referred to as the "iron law of prohibition." Such efforts invariably lead to more dangerous and concentrated compounds becoming available. Fentanyl and its analogues are potent synthetic opioids that have largely replaced the street supply that was once dominated by imported heroin and diverted pharmaceutical drugs. ${ }^{4}$ The withdrawal of heroin appears to be an economic decision made by international drug cartels, while the disappearance of diverted pharmaceutical drugs has followed the decisions of regulators, physicians and law enforcement. Together they have created the overdose epidemic.

The popular narrative for the genesis of the current overdose crisis is irrational prescribing practices of physicians who flooded the market with addictive medications - aided by the unethical marketing of the pharmaceutical industry that promoted these drugs despite knowing the dangers - and sparked an epidemic of opioid addiction. While having a cheap and ready supply of opioid drugs does allow for misuse and addiction, this narrative fails to acknowledge that drug use is largely demand-driven by people seeking to self-medicate to deal with trauma, physical pain, emotional pain, isolation, mental illness and a range of other personal challenges, ${ }^{5}$ and these are the people overdosing.

\section{KEY POINTS}

- Overdose deaths in British Columbia are largely due to potent synthetic opioids.

- A "prohibition" approach that focuses on reducing access to pharmaceutical products directly contributes to exposure to higher risk illicit substances, which has put many people at risk of overdose.

- The public health response to a poisoning epidemic must be to provide a safer alternative, which must include providing a safe supply of pharmaceutical drugs, as well as decriminalization of drug use and a redeployment of resources from enforcement to social and health services.

Primary prevention has an important role in the opioid crisis. Limiting access and exposure to opioids by people who are not currently using these drugs should be a top priority. This is what prompted the widespread uptake of prescription-drug monitoring programs that were designed to identify aberrant patterns of opioid prescribing and opioid use. ${ }^{6}$ However, choosing to focus on primary prevention while not addressing the risks to people already dependent on opioids is deadly policy. With the disappearance of a reliable supply of heroin and major cutbacks in opioid prescriptions, many thousands of Canadians have been put in a position where they must choose between purchasing potent and unpredictable street drugs or abstinence. For many people, abstinence is not an option.

Between 2015 and 2017, fentanyl became the drug that dominated the illegal opioid market in much of North America. At the same time, access to prescription opioids became more difficult. As a result, we are now in the midst of what can only be described as a mass poisoning epidemic. As for any poisoning event, the response should be to provide an alternative to the poison. ${ }^{7}$ Until we provide a safer opioid supply, everyone who purchases drugs from the street could potentially overdose and die.

The call to provide a safer and regulated opioid supply in response to the overdose crisis has become the main theme among advocates and drug user groups who have watched the devastation occurring in their communities. ${ }^{8} \mathrm{~A}$ limited safe supply 
program has been operating in Vancouver for more than a decade as a legacy from a pivotal clinical trial that showed that providing injectable heroin or hydromorphone, under controlled conditions, to people who had not been successful with methadone maintenance therapy resulted in high retention rates and improved social and health outcomes. ${ }^{9}$ It is time to build on lessons from this program and move to unwitnessed, flexible and low-barrier models that are scalable.

In response to the coronavirus disease 2019 pandemic, BC released guidelines that would allow physicians to prescribe opioid medications, along with other restricted drugs, for people needing to isolate. ${ }^{10}$ To date, the uptake has been slow as physicians have generally been reluctant to prescribe the drugs and do not want to be the gatekeepers of a public health program. Technology can also help to expand access to a safer opioid supply. The MySafe project uses a biometric identifying system to allow eligible participants who are unlikely to go to a pharmacy or medical clinic to pick up prescribed hydromorphone tablets through a secure machine. ${ }^{11}$ In addition to directly addressing the toxic drug supply, safe supply initiatives greatly reduce the need to acquire money and drugs through the informal economy, which is life-changing for people caught up in the desperate pursuit of procuring drugs.

Those opposed to a safer opioid supply usually offer reasons previously used to obstruct other harm reduction programs, such as the following: people will not be motivated to stop using drugs, drugs could be diverted, taxpayers should not support illegal activities, and people should be put in drug treatment and recovery programs. Yet forced abstinence does not motivate people to stop using drugs, diverted drugs are safer than illicit fentanyl, we are already spending millions of dollars on ineffective programs, and many people are not prepared to enter drug treatment programs. Meanwhile, massive and tragic loss of life continues, and the health care system is strained.

In the last 5 years, the major responses to the overdose crisis have been to reverse overdoses through harm reduction programs, build a better addiction care system, and create better housing and social services. Although these may be important actions and aspirations in the long term, they will not address the current emergency. Unless there is a radical change in our approach to the epidemic, overdose deaths will continue unabated. It is time to scale up safe supply and decriminalize drug use.

\section{References}

1. Crabtree A, Lostchuck E, Chong M, et al. Toxicology and prescribed medication histories among people experiencing fatal illicit drug overdose in British Columbia, Canada. CMAJ 2020;192:E967-72.

2. British Columbia Coroners Service. Illicit drug toxicity deaths in BC: January 1 , 2010-May 31, 2020. Available: www2.gov.bc.ca/assets/gov/birth-adoption -death-marriage-and-divorce/deaths/coroners-service/statistical/illicit-drug.pdf (accessed 2020 July 9).

3. Beletsky L, Davis CS. Today's fentanyl crisis: Prohibition's Iron Law, revisited. Int J Drug Policy 2017;46:156-9.

4. Colon-Berezin C, Nolan ML, Blachman-Forshay J, et al. Overdose deaths involving fentanyl and fentanyl analogs - New York City, 2000-2017. MMWR Morb Mortal Wkly Rep 2019;68:37-40.

5. Dasgupta N, Beletsky L, Ciccarone D. Opioid crisis: no easy fix to its social and economic determinants. Am J Public Health 2018;108:182-6.

6. Haffajee RL. Prescription drug monitoring programs - Friend or folly in addressing the opioid-overdose crisis? N Engl J Med 2019;381:699-701.

7. Fischer B, Pang M, Tyndall M. The opioid death crisis in Canada: crucial lessons for public health. Lancet Public Health 2019;4:e81-2.

8. Tyndall M. An emergency response to the opioid overdose crisis in Canada: a regulated opioid distribution program. CMAJ 2018;190:E35-6.

9. Oviedo-Joekes E, Brissette S, Marsh DC, et al. Diacetylmorphine versus methadone for the treatment of opioid addiction. N Engl J Med 2009;361:777-86.

10. Ahamad K, Bach P, Brar R, et al. Risk mitigation: in the context of dual public health emergencies. Vancouver: BC Centre on Substance Use (BCCSU); 2020. Available: www.bccsu.ca/wp-content/uploads/2020/04/Risk-Mitigation-in-the -Context-of-Dual-Public-Health-Emergencies-v1.5.pdf (accessed 2020 July 9).

11. Watson B. Vancouver's drug-dispensing machine: why it exists and how it works. CBC News 2020 Jan. 17. Available: www.cbc.ca/news/canada/british -columbia/vancouver-drug-dispensing-machine-opioids-overdoses-1.5429704 (accessed 2020 July 9).

\section{Competing interests: None declared.}

This article was solicited and has not been peer reviewed.

Affiliation: School of Population and Public Health, University of British Columbia, Vancouver, BC

Correspondence to: Mark Tyndall, Mark.Tyndall@ubc.ca, @DrMtyndall 